\title{
Lifestyle and schizophrenia
} Ioannis Christopoulos*, Georgia Massouri, Vassilios Fotopoulos and Themistokles Chamogeorgakis

\author{
Address: Dromokaiteion Psychiatric Hospital, Athens, Greece \\ * Corresponding author
}

from International Society on Brain and Behaviour: 2nd International Congress on Brain and Behaviour Thessaloniki, Greece. 17-20 November 2005

Published: 28 February 2006

Annals of General Psychiatry 2006, 5(Suppl I):S78 doi:I0.II86/1744-859X-5-SI-S78

\section{Background}

Several findings from the basic sciences, show the involvement of the membrane phospholipids in brain functioning. In particular, they are directly involved in all signal transduction cascades and the overall function of all the membrane-bound and membrane-associated proteins. The essentiality of the essntial polyunsaturated fatty acids (EPUFAs) has been established since 1929 by Burr and Burr. There are two types of them: omega-3 and omega- 6 , so named for the position of carbon double bonds in the chain. The principal CNS EPUFAs are: eicosapntaenoic acid (EPA) and docosahexaenoic acid (DHA), both omega-3, and arachidonic acid (AA), which is omega- 6 . Extensive work has shown that AA and DHA metabolism is altered in the very early stages in schizophrenia. Reduced membrane PUFAs have been linked with symptom severity and development of tardive dyskinesia. All the findings taken together support the notion that the molecular changes in membrane phospholipds may be present prior to both clinical and biological manifestations of the disorder. Most studies suggest that both AA and DHA are critically involved in the pathophysiology of schizophrenia, as dietary depletin of them on the foetus, in animal studies, has resulted in significant morphological abnormalities in brain regions, which are also involved in the pathophysiology of schizophrenia.The same studies point at a significant involvement of AA and DHA in the pathophysiology of the disorder. The modern Western diet has changed into a meat and saturated fat one, with asignificant rise in the consumption of seed oils (such as sunflower and soybean), whose PUFA content imainly omega- 6 at the expense of omega-3 (the former have much more inflammatory effects than the latter). The omega- 6 to omega-3 ratio was $0.4-2.8: 1$ in the Palaeolithic and evolutionary diets, but today, especially in the second half of the 20th century, this ratio has risen to
17:1. EPUFAs are also susceptible to peroxidation, which in turn is associated with schizophrenia and compounded by a number of factors, such as the unhealthy lifestyle of the patients with the disorder. Taking all the above into account, it has been proposed that schizophrenia is a membrane lipid disorder that is expressed throughout the body and although the validity of the hypothesis remains unknown, it has been shown beyond doubt, using a variety of methods (including MRS), bith in vivo and postmortem, that there are significant alterations of the phospholipids' biochemistry in the brains and the rest of the body of patients with the disorder. Currently, significant work is under way in the form of measuring the therapeutic effect of interventions aiming to restore the abnormality, involving both pharmacological inerventions and lifestyle changes.

\section{Materials and methods}

We studied and evaluated all the clinical trials (there are now five published placebo controlled double blind trials of eicosapentaenoic acid [EPA] in scizophrenia), open label studies and theories, targeting the membrane phospholipids to date. We compared the results and how the findings from the basic research could guide for nove intrventions

\section{Results}

Four out of five placebo-controlled double blind trials with EPA have shown positive results, but the evidence is rather suggestive than definitive as larger scale trials are needed. At present, the most promising approach is the use of ethyl-EPA at the dose of $2 \mathrm{~g}$. The difference in methodology in the studies is a confounding factor, so this among other issues needs to be amended. Overall the evidence suggests that the hypothesis has substantial founda- 
tions but more interventional options as well as larger scale studies with the existing ones are worth pursuing.

\section{Discussion}

The evidence so far points to a definite membrane phospholipid abnormality in schizophrenia. As more details are revealed by the basic research a more comprehensive theoretical basis is formed, which will enable the design of clinically usefull interventions in this direction. The evidence so far though suggests that every effort by the means of lifestyle (diet is a part of it) change in order to rectify the membrane lipd abnormality is worth trying along the usuall pharmacological inerventions, but more work is needed in both the basic research and clinical levels in order to design succesfull inerventions, following the central theme of therapeutics: "From the bench-to-the bedside"

\section{References}

I. Arvidakshan M, Sitasawad S, et al.: Membrane essential polyunsaturated fatty acids and schizophrenia outcome: EPUFA and lipid peroxide levels in never-medicated and medicated schizophrenics. Biol Psychiatry 2003.

2. Horrobin DF: The membrane phospholipid hypothesis of schizophrenia as a biochemical basis for the neurodevelopmental consept of schizophrenia. Schizophr Res 1998, 30:193-208.

3. Brown S, Birtwistle J, et al.: The unhealthy lifestyle of people with schizophrenia. Psychol Med 1999, 29:697-701.

4. Joy $C B$, Mumby-Croft R, et al.: Polyunsaturated fatty acids supplementation for schizophrenia. Cochrane Database Systematic Reviews 2:CD00I 257.

Publish with Biomed Central and every scientist can read your work free of charge

"BioMed Central will be the most significant development for disseminating the results of biomedical research in our lifetime. "

Sir Paul Nurse, Cancer Research UK

Your research papers will be:

- available free of charge to the entire biomedical community

- peer reviewed and published immediately upon acceptance

- cited in PubMed and archived on PubMed Central

- yours - you keep the copyright

Submit your manuscript here:

http://www.biomedcentral.com/info/publishing_adv.asp 